\title{
SOBRE O ÍNDICE GERAL DE CURSOS (IGC)
}

\author{
Hélio RadKe BittencourT* \\ Alam de Oliveira Casartelli** \\ Alziro César de Morais Rodrigues***
}

Recebido em: 06 de maio de 2009

Aprovado em: 14 de junho de 2009

\begin{abstract}
* Prof. de Estatística da Faculdade de Matemática da Pontifícia Universidade Católica do Rio Grande do Sul (PUCRS) e Doutorando em Geografia pela Universidade Federal do Rio Grande do Sul. E-mail: heliorb@ pucrs.br.

** Prof. da Faculdade de Administração, Contabilidade e Economia da PUCRS, Dr. em Comunicação Social pela PUCRS. E-mail: alam@pucrs.br

*** Prof. da Faculdade de Administração, Contabilidade e Economia da PUCRS, Dr. em Administração pela École des Hautes Études Commerciales (França). E-mail: rodrigues@pucrs.br
\end{abstract}

Resumo: O Índice Geral de Cursos (IGC) é um indicador adotado no ensino superior brasileiro que pretende expressar, em um único número, a qualidade de todos os cursos de graduação, mestrado e doutorado de uma instituição de ensino superior (IES). O IGC considera aspectos relacionados à infraestrutura, recursos didáticos e corpo docente, sendo divulgado anualmente pelo Instituto Nacional de Estudos e Pesquisas Educacionais Anísio Teixeira (INEP). A julgar pelas repercussões decorrentes de sua divulgação em 2008, o IGC tornou-se um potencial e polêmico instrumento de marketing e de influência na formação de opinião pública. Em função disso, é importante não só compreender adequadamente a composição desse indicador, mas igualmente identificar formas de como uma IES pode melhorá-lo. Este artigo enfoca esses dois aspectos, aportando contribuições na discussão sobre o IGC e sobre o Sistema Nacional de Avaliação da Educação Superior (Sinaes).

Palavras-chave: Índice Geral de Cursos. Avaliação da educação superior. Enade. Sinaes.

\section{ON THE GENERAL INDEX FOR PROGRAMS (IGC)}

\begin{abstract}
The General Index for Programs (IGC) is an indicator adopted in Brazilian higher education that seeks to express in a single number, the quality of all undergraduate, master's and doctorate programs in a higher education institution (IES). The IGC is based on aspects related to infrastructure, teaching resources and faculty, and is published annually by the National Institute of Educational Studies and Research Anisio Teixeira (INEP). Considering the effects arising from its results in 2008, the IGC has become a potential and controversial marketing tool to influence public opinion. Thus, it is important not only to properly understand the composition of this indicator, but also to identify how an IES could improve it. This article focuses on these two aspects, providing contributions in the discussion on the IGC and the National Higher Education Evaluation System (Sinaes).
\end{abstract}

Key words: General Index of Courses (IGC). Higher education evaluation. Enade. Sinaes.

\section{Introdução - do Provão ao Enade}

O ensino superior brasileiro tem sido objeto de avaliações em larga escala desde a instituição do Exame Nacional de Cursos em 1996. O Provão, como era mais conhecido, passou a ter caráter obrigatório para os concluintes de cursos superiores por força de lei aprovada pelo Congresso Nacional, tendo sido 
realizado anualmente entre os anos 1996 e 2003 (VIANNA, 2003). De acordo com INEP (2003), o Provão foi criado com o propósito de avaliar o processo de ensino-aprendizagem de cursos de graduação, tendo como principal objetivo contribuir para a melhoria da qualidade de ensino.

O Provão consistia na aplicação de provas para alunos concluintes dos cursos que estavam sendo avaliados. O desempenho nas provas deveria refletir a qualidade do curso realizado pelo aluno. Na última edição do Provão, realizada em 2003, participaram mais de 420 mil formandos em aproximadamente 6 mil cursos de 26 áreas. Mesmo assim, o Provão, foi alvo de muitas críticas, especialmente de alunos e professores (VERHINE; DANTAS; SOARES, 2006). A despeito das críticas originadas dentro da própria comunidade acadêmica, vários gestores universitários passaram a divulgar os resultados do Provão quando lhes parecia conveniente. Por outro lado, a insatisfação por parte de alunos de alguns cursos incentivou a realização de boicotes e protestos cujo mote residia no fato de que um exame realizado unicamente no final do curso não refletia a realidade do processo de formação acadêmica. Alunos de cursos mal avaliados temiam a desvalorização de seu diploma depois de todo esforço para chegar à colação de grau. Em 2004, o Provão foi substituído pelo Exame Nacional de Desempenho de Estudantes (ENADE) que procurou atender a algumas reivindicações. A avaliação dos cursos passou a ser realizada em dois momentos, no início e no final dos mesmos, e os alunos passaram a ser selecionados por amostragem. Com um ciclo de avaliações de cada curso a cada três anos, houve um alinhamento à periodicidade de avaliação trienal adotada pela Coordenação de Aperfeiçoamento de Pessoal de Nível Superior (Capes) para os cursos de pós-graduação stricto-sensu.

O ENADE é o elemento de mais notoriedade do Sistema Nacional de Avaliação da Educação Superior (SINAES), instituído que foi pela lei 10.861, aprovada em 2004. O SINAES também inclui outras dimensões, tais como uma auto-avaliação das IES, uma avaliação externa e uma avaliação específica de cada curso de graduação, realizada por avaliadores selecionados pelo Ministério de Educação (MEC). De acordo com Bittencourt et al. (2008), ainda que o SINAES consista de um processo completo de avaliação, a maioria das IES e os meios de comunicação dão mais destaque aos resultados derivados do ENADE. Esse aspecto é destacado por Ristoff e Giolo (2006) que afirmam que grande parte da sociedade, da imprensa e até mesmo os próprios alunos pensam que o SINAES se resume ao ENADE.

Com todos os esforços do INEP para aperfeiçoar o processo do ENADE nos últimos anos, as outras dimensões do SINAES tornaram-se coadjuvantes 
menos lembradas. Dias Sobrinho (2008), Barreyro (2008), Brito (2008) e Giolo (2008) são enfáticos ao relatar a perda de foco original do SINAES e a exagerada importância ao ENADE. Para Brito (2008), o ENADE regrediu desde a sua concepção em 2004, no entanto, percebe-se que o mesmo vem passando por modificações que buscam aprimorar o processo de avaliação, como o aumento gradual no número de cursos avaliados, a universalização do exame e a criação de novos conceitos. O quadro 1, a seguir, apresenta a evolução do ENADE em termos de número de estudantes e de cursos participantes por edição, bem como os conceitos divulgados em cada edição.

\begin{tabular}{|r|c|c|c|c|}
\hline $\begin{array}{c}\text { Ano de } \\
\text { referência }\end{array}$ & $\begin{array}{c}\text { Divulgação dos } \\
\text { resultados }\end{array}$ & $\begin{array}{c}\text { Número de } \\
\text { estudantes }\end{array}$ & $\begin{array}{c}\text { Número } \\
\text { de cursos }\end{array}$ & $\begin{array}{c}\text { Conceitos } \\
\text { divulgados }\end{array}$ \\
\hline 2004 & Jul/2005 & 140.340 & 2.184 & ENADE \\
\hline 2005 & Ago/2006 & 277.476 & 5.511 & $\begin{array}{c}\text { ENADE } \\
\text { IDD }\end{array}$ \\
\hline 2006 & Mai/2007 & 386.524 & 5.388 & $\begin{array}{c}\text { ENADE } \\
\text { IDD }\end{array}$ \\
\hline 2007 & Ago/2008 & 189.614 & 3.239 & $\begin{array}{c}\text { ENADE } \\
\text { IDD } \\
\text { CPC }\end{array}$ \\
\hline 2008 & $\begin{array}{c}\text { Ainda não } \\
\text { divulgado }\end{array}$ & $491.502^{\mathrm{a}}$ & $24.842^{\mathrm{b}}$ & $\begin{array}{c}\text { ENADE } \\
\text { IDD } \\
\text { CPC } \\
\text { IGC }\end{array}$ \\
\hline
\end{tabular}

Quadro 1: Número de estudantes e cursos por edição do ENADE

Fonte: MEC-INEP.

${ }^{a}$ Previsão.

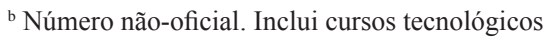

O número de alunos e cursos avaliados em cada edição apresentou forte crescimento no período. Deve-se considerar que como o ciclo de avaliações é trienal algumas comparações não fazem sentido. Salienta-se, portanto, que o ano $t$ deve ser comparado com o ano $t+3$. Sendo assim, de 2004 para 2007 houve incremento de $45 \%$ no número de estudantes e $58 \%$ no número de cursos avaliados. De 2005 para 2008, o número de estudantes cresceu 77\% e o número de cursos quase quintuplicou, embora tais números sejam ainda não oficiais.

O número de conceitos adotados e divulgados pelo MEC aumentou de um para quatro. Na primeira edição era divulgado apenas o conceito ENADE, derivado do desempenho de alunos ingressantes e concluintes nas provas. Em 2005 foi instituído o Índice de Diferença de Desempenho (IDD) pelo INEP procurando responder a críticas que apontavam um possível favorecimento de 
instituições públicas na obtenção de conceitos mais elevados influenciados pelo nível dos alunos ingressantes. O Conceito Preliminar de Curso (CPC), instituído em 2007, sintetiza, por outro lado, os resultados dos conceitos ENADE e IDD num único valor e baseia-se em outros fatores, conforme explicado na seção 2 adiante. Em 2008, com a divulgação do Índice Geral de Cursos (IGC) inicia-se uma nova etapa nas avaliações em larga escala e as IES passam a ter seu IGC divulgado anualmente.

A grande repercussão da divulgação do IGC pela imprensa transformou este indicador num poderoso e polêmico instrumento de marketing institucional e de formação de opinião pública. Barreyro (2008) teme, no entanto, que a divulgação de novos indicadores se aproxime mais de visibilidade publicitária do que, propriamente, da avaliação da qualidade. Dias Sobrinho (2008) questiona o conceito de qualidade no ensino superior, não concordando com a aplicação dos atuais instrumentos para mensuração da qualidade de cursos. Para esse autor, o procedimento atual não respeita as especificidades institucionais inicialmente previstas.

Com todas essas considerações, e ainda que o SINAES possa ter perdido o foco de sua proposta original, acredita-se ser possível retomar o propósito de uma avaliação mais efetiva considerando outras dimensões sem, no entanto, desqualificar o ENADE. Deveriam ocupar posições equivalentes a valorização do processo de avaliação institucional, a ampla divulgação dos resultados de avaliações in loco e da qualificação do corpo docente, assim como os conceitos derivados do ENADE.

Contudo, apesar das críticas, não há como prescindir de uma avaliação do aprendizado de alunos por meio de exames ou provas em avaliações de larga escala. Portanto, há que se defender, mesmo que de forma parcial, a realização do ENADE, sustentando que o pleno entendimento da composição dos indicadores derivados desse exame pode trazer valiosas informações e insights às instituições envolvidas. Com esse propósito, este artigo procura esclarecer o mais novo indicador derivado do ENADE: o IGC. As seções subsequentes apresentam o detalhamento deste indicador institucional, os resultados de 2008 e sua discussão, além de um modelo de decomposição e simulação de cenários futuros.

\section{O Índice Geral de Cursos (IGC)}

O IGC é um indicador que busca expressar a qualidade de todos os cursos de graduação, mestrado e doutorado de uma Instituição de Ensino Superior (IES), 
distribuídos na totalidade de campi e municípios onde atua. Na primeira edição de uso desse indicador, o INEP emitiu conceitos para 173 universidades, 131 centros universitários e 1.144 faculdades isoladas e integradas. (INEP, 2008)

O índice IGC depende fortemente da média do CPC (Conceito Preliminar de Cursos) e, em menor grau, da média dos conceitos dos programas de pósgraduação de cada IES. O CPC, por sua vez, apresenta a seguinte composição e ponderações:

- $\operatorname{ENADE}^{*}(40 \%)$

- $\operatorname{IDD}^{*}(30 \%)$

- Instalações e infraestrutura* (3\%)

- Recursos didáticos* (8\%)

- Percentual de doutores (12\%)

- Percentual de professores com tempo integral (7\%)

Os itens assinalados com um asterisco totalizam $81 \%$ e decorrem do desempenho dos alunos (ENADE e IDD) ou de avaliações por eles realizadas no questionário sócio-econômico sobre instalações, infraestrutura e recursos didáticos. O restante da composição do CPC, 19\% relativos aos percentuais de doutores e de professores com tempo integral, provêm de avaliação baseada em informações disponibilizadas diretamente pela IES.

O IGC de uma IES é calculado ponderando-se a média dos conceitos CPC dos cursos de graduação (esta também ponderada pela quantidade de alunos matriculados em cada curso) pelo "peso” da graduação na instituição. O mesmo cálculo é feito com os cursos de pós-graduação stricto sensu, em nível de mestrado e doutorado. A equação que resulta no IGC é apresentada pelo INEP da seguinte forma (INEP, 2008):

$$
\mathrm{I}=\alpha \mathrm{G}+\frac{(1-\alpha) \beta}{2}(\mathrm{M}+5)+\frac{(1-\alpha)(1-\beta)}{3}(\mathrm{D}+10)
$$

sendo

$$
\alpha=\frac{T_{G}}{T_{G}+T_{M E}+T_{D E}} \quad \text { e } \quad \beta=\frac{T_{G}}{T_{M E}+T_{M E}}
$$

Com o objetivo de facilitar a compreensão desta equação para leitores não familiarizados com a linguagem matemática, reescreve-se a mesma de uma forma mais simples: onde:

$$
\text { IGC }=\left\{\left[\mathbf{P}_{\text {Grad }} \times \mathrm{G}\right]+\left[\mathbf{P}_{\text {Mest }} \times(\mathbf{M}+5) / 2\right]+\left[\mathbf{P}_{\text {Dout }} \times(\mathrm{D}+10) / 3\right]\right\} \times 100
$$


G = média ponderada dos CPCs da IES nos cursos de graduação, onde a ponderação dá-se de acordo com o número de alunos matriculados em cada curso.

$\mathbf{M}=$ média ponderada dos conceitos CAPES nos programas de pós-graduação, nível de Mestrado, onde a ponderação dá-se de acordo com o número de alunos matriculados no programa em nível de Mestrado. O conceito de tais cursos é limitado a 5 .

D = média ponderada dos conceitos CAPES nos programas de pós-graduação, nível de Doutorado, onde a ponderação dá-se de acordo com o número de alunos matriculados no programa em nível de Doutorado. Os conceitos são subtraídos de 2 para permitir comparação com os cursos de Mestrado.

$\mathbf{P}_{\text {Grad }}, \mathbf{P}_{\text {Mest }}$ e $\mathbf{P}_{\text {Dout }}=$ percentual de alunos de graduação, mestrado e doutorado. Deve-se salientar que tais percentuais não são calculados diretamente pelo número de alunos matriculados. Isso ocorre porque alunos de pós-graduação têm peso maior do que alunos de graduação. Os pesos são iguais ao conceito obtido pelo programa, subtraído de 2 . No caso de mestrados, o conceito é limitado a 5 .

O IGC resultante varia em um intervalo de 0 a 500 pontos $^{1}$, sendo que as extremidades constituem valores pouco prováveis em virtude da metodologia de cálculo. Para classificação das IES, o IGC contínuo é transformado em conceito. A métrica dessa transformação é apresentada na tabela 1 .

Tabela 1 - Métrica de transformação do IGC contínuo em conceito

\begin{tabular}{cc}
\hline IGC contínuo & Conceito IGC associado \\
\hline $000-094$ pontos & 1 \\
$095-194$ pontos & 2 \\
$195-294$ pontos & 3 \\
$295-394$ pontos & 4 \\
$395-500$ pontos & 5 \\
\hline
\end{tabular}

Fonte: MEC/INEP, 2008

1 Nota técnica do INEP sobre o IGC (2008) utiliza notação ligeiramente distinta e omite o termo de multiplicação por 100 que transforma a escala de 0-5 pontos para 0-500 pontos. 


\section{Resultados do IGC em âmbito nacional}

Os resultados do IGC em 2008, em âmbito nacional, revelam grande heterogeneidade entre as IES, com uma amplitude de variação de 428 pontos nesse indicador. Em média, Universidades apresentaram melhores resultados, seguidas de Centros Universitários e de Faculdades, conforme mostra a tabela 2 a seguir. Analisando-se a variabilidade dos resultados, os Centros Universitários apresentaram menor variação, tanto absoluta quanto relativa. A figura 1 mostra a grande concentração de IES na faixa referente ao conceito 3 (195-294 pontos).

Tabela 2 - Estatísticas descritivas para o IGC contínuo por tipo de IES

\begin{tabular}{lcccc}
\hline \multirow{2}{*}{ Organização acadêmica } & \multicolumn{4}{c}{ IGC Continuo } \\
\cline { 2 - 5 } & Mínimo & Máximo & Média & Desvio-padrão \\
\hline Universidades & 149 & 439 & 271,96 & 60,56 \\
Centros Universitários & 133 & 380 & 232,77 & 42,45 \\
Faculdades e Outras & 55 & 483 & 214,49 & 56,13 \\
\hline
\end{tabular}

Fonte: INEP, 2009

A figura 1 sugere que o IGC tem um comportamento gaussiano, independentemente do tipo de IES. A destacar que o grupo das faculdades apresenta um pequeno acúmulo de IES acima dos 400 pontos, formado por 15 instituições que obtiveram conceito máximo (tabela 3). Contudo, é nesse grupo que se encontram as nove instituições brasileiras que receberam conceito mínimo.

A maioria das IES foi classificada com conceito 3, sendo que as universidades constituem o grupo com o maior percentual de instituições acima desse patamar (30,4\%).

Dentre os 21 cursos cujo IGC contínuo credenciou ao conceito 5, 13 deles foram obtidos por IES com apenas um ou dois cursos com conceito ENADE. Os quatro conceitos IGC contínuos mais altos foram obtidos por faculdades privadas com apenas um curso de graduação avaliado. Apenas duas instituições de grande porte, ambas universidades federais com mais de 20 mil matrículas de graduação, figuram na lista das IES com conceito máximo. 

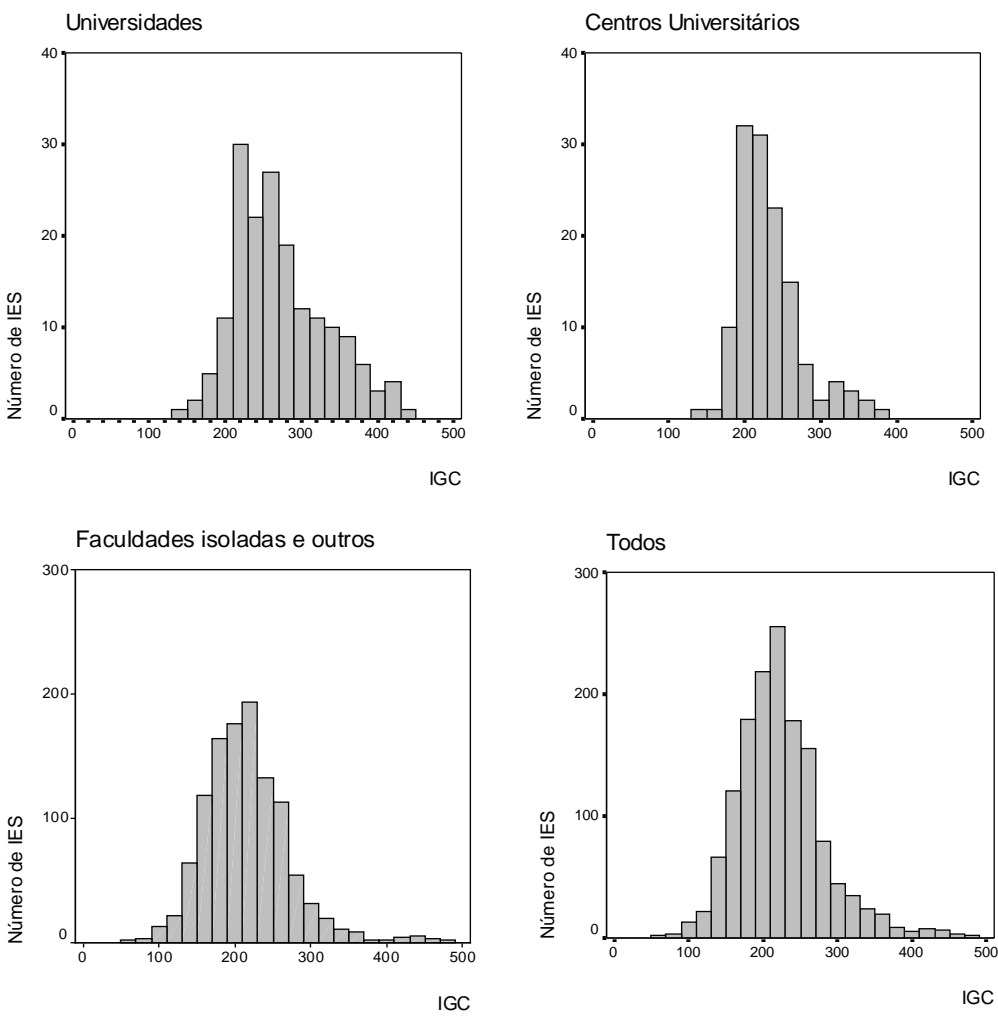

Figura 1: Histogramas do IGC contínuo de Universidades, Centros Universitários, Faculdades isoladas e outros e de todas IES independentemente da categoria administrativa.

Fonte: INEP, 2009

Tabela 3 - Distribuição dos conceitos por tipo de IES

\begin{tabular}{l|rrrrr|r}
\hline \multirow{2}{*}{ Organização acadêmica } & \multicolumn{7}{|c}{ IGC Conceito } & \multicolumn{2}{c}{ Total } \\
\cline { 2 - 6 } Universidades & 1 & 2 & 3 & 4 & 5 & 174 \\
& 0 & 9 & 112 & 47 & 6 & $100,0 \%$ \\
\hline \multirow{2}{*}{ Centros Universitários } & $0,0 \%$ & $5,2 \%$ & $64,4 \%$ & $27,0 \%$ & $3,4 \%$ & 131 \\
& 0 & 16 & 103 & 12 & 0 & $13 \%$ \\
\hline \multirow{2}{*}{ Faculdades e Outras } & $0,0 \%$ & $12,2 \%$ & $78,6 \%$ & $9,2 \%$ & $0,0 \%$ & $100,0 \%$ \\
\hline \multirow{2}{*}{ Total } & 9 & 420 & 638 & 63 & 15 & 1145 \\
& $0,8 \%$ & $36,7 \%$ & $55,7 \%$ & $5,5 \%$ & $1,3 \%$ & $100,0 \%$ \\
\hline
\end{tabular}

Fonte: INEP, 2009 


\section{Decomposição do IGC}

O monitoramento do IGC e o pleno entendimento de sua composição permitem transcender a simplificação de um rótulo gerado pela divulgação de um conceito ou posição em um ranking. Ainda que a formulação do IGC seja, à primeira vista, um pouco complexa, é possível compreendê-la e monitorá-la por meio de uma planilha eletrônica, permitindo à IES vislumbrar cenários futuros a partir de prováveis alterações de conceito. A tabela 4 apresenta dados de uma IES hipotética, denominada Épsilon, com dados fictícios que permitirão uma exemplificação completa.

Tabela 4 - Matrículas e avaliação de graduação e pós-graduação para a IES Épsilon

\begin{tabular}{|c|c|c|c|c|}
\hline & & \multicolumn{2}{|c|}{ Matrículas } & Conceitos \\
\hline & & \multicolumn{2}{|c|}{ Graduação } & $C P C$ \\
\hline \multirow{9}{*}{ Graduação } & Administração & \multicolumn{2}{|c|}{1350} & 3 \\
\hline & Ciências Contábeis & \multicolumn{2}{|c|}{830} & 3 \\
\hline & Direito & \multicolumn{2}{|c|}{2300} & 3 \\
\hline & Economia & \multicolumn{2}{|c|}{250} & 4 \\
\hline & Engenharia Elétrica & \multicolumn{2}{|c|}{430} & 4 \\
\hline & Engenharia Civil & \multicolumn{2}{|c|}{420} & 3 \\
\hline & História & \multicolumn{2}{|c|}{240} & 5 \\
\hline & Geografia & \multicolumn{2}{|c|}{180} & 2 \\
\hline & & Mestrado & Doutorado & CAPES \\
\hline \multirow{3}{*}{ Pós-graduação } & Administração & 70 & 30 & 5 \\
\hline & Engenharia Elétrica & 35 & - & 3 \\
\hline & História & 45 & 20 & 6 \\
\hline
\end{tabular}

Obs.: IES e dados fictícios.

Partindo-se dos dados de número de matrículas e conceitos, os primeiros cálculos que devem ser efetuados a seguir são: a) somatório do número de matrículas na graduação e b) número de alunos de pós-graduação em termos de graduando equivalente, que é calculado multiplicando-se o número de alunos do programa de mestrado ou doutorado pelo conceito do curso subtraído de duas unidades. Tais valores permitirão definir três termos da fórmula do IGC: $\mathbf{P}_{\text {Grad }}, \mathbf{P}_{\text {Mest }}$ e $\mathbf{P}_{\text {Dout }}$. O quadro 2 a seguir apresenta o cálculo dos componentes de ponderação do IGC da IES Épsilon. 


$$
\begin{aligned}
& \text { Alunos de Graduação }=1350+830+\ldots+180=6000 \\
& \text { Alunos de Mestrado }=(70 \times(5-2))+(35 \times(3-2))+(45 \times(5-2))=380 \\
& \text { Alunos de Doutorado }=(30 \times(5-2))+(20 \times(6-2))=170 \\
& P_{\text {Grad }}=6000 /(6000+380+170)=91,6 \% \\
& \mathbf{P}_{\text {Mest }}=380 /(6000+380+170)=5,8 \% \\
& \mathbf{P}_{\text {Dout }}=170 /(6000+380+170)=2,6 \%
\end{aligned}
$$

${ }^{\text {a }}$ Conceito de mestrado é limitado em 5 para efeito de ponderação.

Quadro 2: Cálculo dos componentes de ponderação do IGC para a instituição Épsilon

A segunda parte dos cálculos reside no cômputo dos componentes G (Graduação), M (Mestrado) e D (Doutorado). Esses números refletem a avaliação média dos cursos numa escala que varia de 1 a 5 (quadro 3).

$$
\begin{aligned}
& G=\frac{(1350 \times 3)+(830 \times 3)+\ldots+(180 \times 2)}{6000}=3,16 \\
& M^{a}=\frac{((70 \times 5)+(35 \times 3)+(45 \times 5))}{150}=4,53 \\
& D=\frac{(30 \times(5-2))+(20 \times(6-2))}{50}=3,40 \\
& { }^{a} \text { Conceito de mestrado é limitado em “5”. }
\end{aligned}
$$

Quadro 3: Cálculo dos componentes G, M e D para a instituição Épsilon

Como todos os componentes variam numa escala comum de 1 a 5 pontos é possível comparar o desempenho dos cursos da IES Épsilon nos três níveis: graduação, mestrado e doutorado. Um simples gráfico de colunas desses resultados auxilia na interpretação dos componentes do IGC. No caso da Épsilon os cursos de mestrado estão próximos do valor máximo (5), visto que o único curso que não pontuou com o valor máximo é exatamente aquele com menor número de alunos. Salienta-se que os componentes G e D, se vistos separada- 
mente, estão dentro da mesma faixa de variação correspondente ao conceito “4” (2,95-3,94, de média ou 295-394 pontos), enquanto o componente M corresponde ao conceito “5” (3,95-5,00, de média ou 395-500 pontos).

A equação a seguir apresenta o cálculo do IGC para a IES hipotética Épsilon: IGC $=\{[91,6 \% \times 3,16]+[5,8 \% \times(4,53+5) / 2]+[2,6 \% \times(3,40+10) / 3]\} \times 100 \cong$ $\cong 289+28+12 \cong 329$ pontos

A graduação é a grande responsável pelo resultado obtido de 329 pontos, que credenciou a Épsilon ao conceito IGC $=4$. Para a instituição conhecer o peso absoluto e relativo de cada curso na composição do IGC sugere-se a construção de uma planilha eletrônica a partir dos dados da Tabela 4, conforme mostra a tela reproduzida na figura 2 . É importante que a planilha seja toda programada com as fórmulas do IGC para possibilitar simulações.

\begin{tabular}{|c|c|c|c|c|c|c|c|}
\hline 国 & Arquivo Editar & Inserir & Formatar & erramentas & İanela & Ajuda & \\
\hline & A & $\mathrm{B}$ & $\mathrm{C}$ & $\mathrm{D}$ & $E$ & $\mathrm{~F}$ & $\mathrm{G}$ \\
\hline 1 & Cursos & Mive! & Graduafäo & Conceitos & $\begin{array}{c}\text { Participação } \\
\text { absoluta no } \\
\text { IGC }\end{array}$ & $\begin{array}{c}\text { Participação } \\
\text { relativa no } \\
\text { IGC }\end{array}$ & $\begin{array}{l}\text { Impacto no IGC } \\
\text { para aumento de } \\
\text { ponto no conceito }\end{array}$ \\
\hline 2 & Adtrinistração & Graduação & 1350 & 3 & 61,8 & $18,8 \%$ & 20,64 \\
\hline 3 & Ciências Contábeis & Graduação & 830 & 3 & 38,0 & $11,6 \%$ & 12,69 \\
\hline 4 & Direito & Graduação & 2300 & 3 & 105,3 & $32,0 \%$ & 35,15 \\
\hline 5 & Economia & Graduação & 250 & 4 & 15,3 & $4,7 \%$ & 3,78 \\
\hline 6 & Engenharia Elétrica & a Graduação & 430 & 4 & 26,3 & $8,0 \%$ & 6,52 \\
\hline 7 & Engenharia Ciwil & Graduação & 420 & 3 & 19,2 & $5,8 \%$ & 6,45 \\
\hline 8 & História & Graduação & 240 & 5 & 18,3 & $5,6 \%$ & 3,68 \\
\hline 9 & Geografia & Graduação & 180 & 2 & 5,5 & $1,7 \%$ & 2,74 \\
\hline 10 & Adruinistraçäo & Mestrado & 70 & 5 & 13,5 & 4,190 & 0,00 \\
\hline 11 & Engenharia Elétrica & 1 Mestrado & 35 & 3 & 5,4 & $1,6 \%$ & 0,69 \\
\hline 12 & História & Mestrado & 45 & 6 & 8,7 & $2,6 \%$ & 0,000 \\
\hline 13 & Adtrinistração & Dout.orado & 30 & 5 & 6,8 & $2,1 \%$ & 0,48 \\
\hline 14 & História & Doutorado & 20 & 6 & 4,9 & $1,5 \%$ & 0,3 \\
\hline 15 & & & & Totais & 329,0 & $100,0 \%$ & 93,12 \\
\hline \multicolumn{8}{|l|}{16} \\
\hline 17 & Componentes & $\mathrm{G}$ & 3,16 & & & & \\
\hline 18 & do IGC & M & 4,53 & & & & \\
\hline 19 & & D & 3,40 & & & & \\
\hline \multicolumn{8}{|l|}{20} \\
\hline 21 & Wúmero de & Graduação & 6000 & & & & \\
\hline 22 & alunos & Mestrado & 380 & & & & \\
\hline 23 & & Doutorado & 170 & & & & \\
\hline \multicolumn{8}{|l|}{24} \\
\hline 25 & Percentuais & Graduação & $91,6 \%$ & & & & \\
\hline 26 & para ponderação & Mestrado & $5,8 \%$ & & & & \\
\hline 27 & & Doutorado & $2,6 \%$ & & & & \\
\hline
\end{tabular}

Figura 2: Exemplo de planilha eletrônica para decomposição do IGC 
O impacto resultante do aumento de um ponto nos conceitos CPC ou Capes tem diferentes respostas no IGC. Pode-se verificar que o impacto varia de 0 até 35,15 pontos por curso. Se o curso de Direito aumentar do conceito CPC=3 para o conceito 5, a Épsilon incrementaria o seu IGC em 70,3 pontos (2×35,15), atingindo com folga o conceito máximo, desde que não houvesse alterações nos demais cursos. O impacto da pós-graduação é pequeno no IGC dessa IES. Uma simulação realizada na planilha mostrou que se todos os cursos tivessem conceito máximo, o impacto seria de 6,4 pontos.

A decomposição do IGC também permite verificar a contribuição de cada curso de graduação e de pós-graduação no resultado total (329 pontos). Na instituição Épsilon, o curso de Direito foi responsável por 105,3 pontos do IGC, ou seja, 32,0\% do total. Somados, os cursos de Direito, Administração e Ciências Contábeis respondem, juntos, por 62,3\% do IGC, o que sugere que o conceito dessa instituição dependa fortemente do desempenho de três cursos de graduação, conforme mostra o diagrama de Pareto da figura 3.

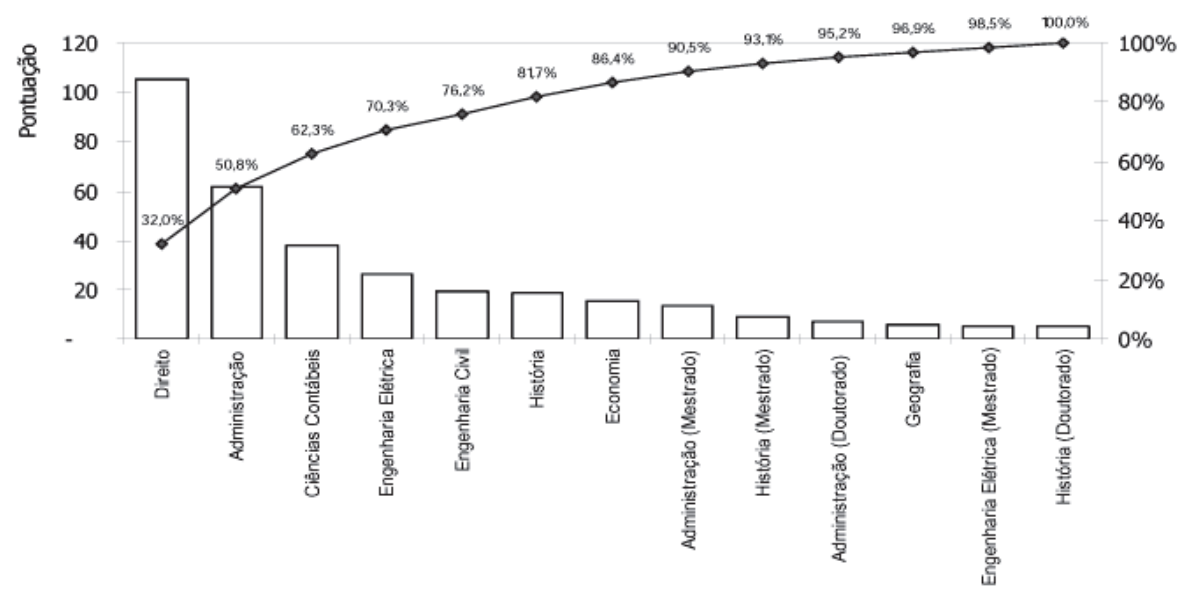

Figura 3: Diagrama de Pareto aplicado na decomposição do IGC da instituição Épsilon

Ainda que todos os cursos, independentemente de seu impacto no IGC, devam buscar excelência, a ponderação de cada um deles no IGC de uma IES deve ser tratada com cuidado e de forma reservada visto que a informação da existência de cursos com peso muito baixo poderia gerar uma desmotivação com relação ao ENADE. 


\section{Considerações finais}

Este texto apresentou uma breve retrospectiva das avaliações em larga escala do ensino superior brasileiro, trazendo uma visão sobre o status atual do SINAES e, mais especificamente, detalhando a composição e os resultados do IGC, último indicador criado pelo INEP.

Não parecem restar dúvidas de que os conceitos derivados do ENADE, em especial o IGC, tornaram-se importantes instrumentos de marketing no setor do ensino superior. A divulgação de rankings tem ocupado nobres espaços da imprensa em todo território nacional tão logo os resultados são publicados. Além disso, o ENADE tem recebido importância demasiada por parte dos órgãos governamentais, o que pode caracterizar uma perda de foco em relação à proposta original do SINAES.

Diante desse quadro, a indagação que se impõe está relacionada a entender por que isso tem acontecido. Algumas reflexões são possíveis. Em primeiro lugar, a forma de divulgação dos resultados do ENADE - realizada em uma única vez - favorece a construção de rankings e a comparação entre IES. Em segundo lugar, há os resultados das avaliações institucionais (interna e externa) que não são divulgados simultaneamente e tampouco nos meios de massa, ficando quase que somente restritos ao público interno das IES. Por fim, há o interesse natural do público em geral por resultados comparativos e rankings.

Agregar os resultados do ENADE e das avaliações interna e externa, seria, sem dúvida, um passo importante para a retomada da proposta original do SINAES. Isso poderia se concretizar na forma de um sistema que compilasse os resultados das avaliações institucionais realizadas in loco pelo MEC/INEP, mostrando-os junto com os resultados do ENADE. Além disso, o IGC deveria considerar também resultados da Avaliação Externa.

Atualmente, o IGC valoriza o desempenho dos alunos no ENADE e suas respostas em relação a duas questões do questionário sócio-econômico. Outras questões do instrumento (que em 2007 tinha 110 questões) também podem vir a ser contempladas em edições futuras. Um aspecto adicional que merece ser revisto é a forma de pontuar os percentuais de doutores nas IES. Hoje, por exemplo, uma IES que cumpre com o requisito de $1 / 3$ de doutores fica com uma pontuação muito baixa neste quesito, especialmente devido aos altos índices de doutores nas universidades federais. O mesmo ocorre em relação a professores em regime de tempo integral. A política salarial de IES públicas incentiva professores em regime de dedicação exclusiva. Em contrapartida, uma IES privada não pode prescindir de professores horistas, especialmente 
porque há muita concentração de alunos num só turno e é desejável que haja professores com experiência profissional na sua área de atuação.

Outro problema que o IGC apresenta, e que se mostra de difícil solução, diz respeito ao detalhamento dos componentes $\mathrm{G}, \mathrm{M}$ e D, mostrados na seção 4. Apesar de o método de cálculo do IGC, proposto pelo INEP, mostrar-se correto e imparcial, pode ocorrer que uma IES de médio ou grande porte venha a ter uma dependência exagerada do desempenho de dois ou três cursos de graduação. Direito, Administração e Pedagogia são cursos que, geralmente, concentram um grande número de alunos e que, portanto, tendem a ter forte impacto no IGC, mesmo em se tratando de uma universidade de grande porte. Por outro lado, cursos de licenciatura, como História, Geografia e Matemática, reconhecidamente com um número menor de alunos, terão um impacto muito pequeno. A fixação de um peso máximo por curso no cálculo do IGC seria uma possível solução para este problema.

Os resultados do IGC divulgados em 2008 propiciaram notoriedade a algumas pequenas faculdades que obtiveram conceito máximo. Deve-se salientar que os cinco maiores IGC's ocorreram em IES com apenas um curso de graduação avaliado. Fica evidenciado que para uma instituição de grande porte, com muitos cursos de graduação e vários programas de mestrado e doutorado, é bem mais complexo obter um conceito máximo. É provável que este seja o motivo pelo qual, no grupo de 21 IES com conceito máximo, há 13 faculdades com um ou dois cursos de graduação. Ainda que, em contrapartida, os menores IGC's tenham sido registrados em pequenas faculdades.

De um modo geral, as universidades e centros universitários apresentaram alta concentração na faixa de pontuação correspondente ao conceito “3”. A diferença no nível de complexidade subjacente ao IGC faz com que a decisão do INEP de divulgar separadamente os resultados por faculdades, centros universitários e universidades tenha sido acertada. O mesmo não se pode dizer da divulgação do IGC contínuo. Se o INEP tivesse divulgado somente os conceitos, como o faz a CAPES na pós-graduação, muitas das críticas não ocorreriam, pois seria mais difícil construir um ranking a partir de conceitos. Isso sugere uma mudança na divulgação dos resultados do IGC contínuo, passando a ser de acesso restrito a cada instituição para que, a partir dos resultados obtidos, pudesse melhor administrar seus processos internos.

Por outro lado, a prática de construção de rankings é comum em todo o mundo. O famoso ranking de Shanghai (ARWU), por exemplo, ordena universidades de todo o mundo com o respaldo da Universidade Shanghai Jiao Tong. Esse ranking segue critérios bem definidos de qualidade de ensino, qualidade 
da instituição, premiações, produção bibliográfica e citações. Na Inglaterra, o jornal The Guardian (GUARDIAN) mantém um site atualizado, onde aspectos de empregabilidade e qualidade de ensino de cursos de graduação são pontuados e listados por universidade do Reino Unido, separadamente por área. Essa prática também é comum nos Estados Unidos onde publicações que avaliam as universidades são comercializadas e o valor atribuído ao diploma difere muito de acordo com a instituição.

No Brasil, além dos rankings construídos a partir do IGC, os resultados das avaliações do ensino de graduação e de pós-graduação passaram a ganhar mais espaço. Os conceitos resultantes da avaliação da CAPES, por exemplo, passaram a figurar ao lado da titulação do pesquisador, se obtida em instituições brasileiras. Diante disso, pode-se prever que o mesmo passará a ocorrer com os cursos de graduação nos próximos anos.

Apesar das críticas ao sistema de avaliação do ensino superior, várias delas aqui elencadas, não há, entretanto, como discordar de Dias, Horiguela e Marchelli (2006) quando afirmam que os procedimentos para avaliação de cursos e de instituições de ensino superior, no Brasil, vêm apresentando uma evolução gradual e consistente. Essa avaliação é essencial para um ensino superior de qualidade no país. Este artigo procurou trazer contribuições à compreensão e ao aprofundamento desse tema.

\section{Referências}

ARWU. Academic ranking of world universities. Disponível em: <www. arwu.org>. Acesso em: 20 abr. 2009.

BARREYRO, Gladys B. De exames, rankings e mídia. Avaliação, Campinas; Sorocaba, v. 13, n. 3, p. 863-868, nov. 2008.

BITTENCOURT, Hélio R.; VIALI, Lorí; CASARTELLI, Alam O.; RODRIGUES, Alziro C. M. Uma análise da relação entre os conceitos ENADE e IDD. Estudos em Avaliação Educacional, São Paulo, v. 19, p. 247-262, 2008.

BRITO, Márcia Regina F. de. O SINAES e o ENADE: da concepção à implantação. Avaliação, Campinas; Sorocaba, v. 13, n. 3, p. 841-850, nov. 2008. 
DIAS, Carmen L.; HORIGUELA, Maria de Lourdes M.; MARCHELLI, Paulo Sérgio. Políticas para a avaliação da qualidade do ensino superior no Brasil: um balanço crítico. Educação e Pesquisa, São Paulo, v. 32, n. 3, p. 435-64, set. 2006.

DIAS SOBRINHO, José. Qualidade, avaliação: do SINAES a índices. Avaliação, Campinas; Sorocaba, v. 13, n. 3, p. 817-825, nov. 2008.

GIOLO, Jaime. "SINAES” intermitentes. Avaliação, Campinas; Sorocaba, v. 13, n. 3, p. 851-856, nov. 2008.

GUARDIAN. The Guardian University Guide. Disponível em: <www. guardian.co.uk/education/universityguide>. Acesso em 20 Abril 2009.

INEP - INSTITUTO NACIONAL DE ESTUDOS E PESQUISAS EDUCACIONAIS ANÍSIO TEIXEIRA. Exame Nacional de Cursos 2003: relatório síntese. Brasília, DF, 2003.

INEP - INSTITUTO NACIONAL DE ESTUDOS E PESQUISAS EDUCACIONAIS ANÍSIO TEIXEIRA. Cálculo do Índice Geral de Cursos: nota técnica. Brasília, DF, 2008.

INEP - INSTITUTO NACIONAL DE ESTUDOS E PESQUISAS EDUCACIONAIS ANÍSIO TEIXEIRA. Resultados do IGC. Disponível em: <http://www.inep.gov.br/areaigc/>. Acesso em: mar. 2009.

RISTOFF, Dilvo; GIOLO, Jaime. O SINAES como Sistema. RBPG, Brasília, v. 3, n. 6, p. 193-213, dez. 2006.

VERHINE, Robert; DANTAS, Lys Maria V.; SOARES, José. F. Do provão ao ENADE: uma análise comparativa dos exames nacionais utilizados no Ensino Superior Brasileiro. Ensaio, Rio de Janeiro, v. 14, n. 52, p. 291-310, jul. 2006.

VIANNA, Heraldo M. Avaliações nacionais em larga escala: análises e propostas. São Paulo: DPE: 2003. 41p. (Textos FCC, n. 23) 